\title{
MOBILIÁRIOS PARA ACAMPAMENTOS TEMPORÁRIOS PLANEJADOS: PROPOSTA DE CLASSIFICAÇÃO
}

\section{FURNITURE FOR TEMPORARY PLANNED CAMPS: CLASSIFICATION PROPOSAL}

Nadieli de Araujo ${ }^{1}$; Lisiane Ilha Librelotto ${ }^{1}$; Paulo Cesar Machado Ferroli ${ }^{1}$, Luana Toralles Carbonari $^{1}$; Thais Nolio Santa Cruz ${ }^{1}$.

${ }^{1}$ Universidade Federal de Santa Catarina, Grupo de Pesquisa VirtuHab.

\section{PALAVRAS CHAVE}

Materiais; Mobiliário para Acampamentos Planejados; Sustentabilidade

\section{KEY WORDS}

Materials; furniture for planned camps; Sustainability

\section{RESUMO}

O mobiliário é característico da civilização humana e vem sendo utilizado há mais de 15.000 anos, possuindo características distintas conforme o uso. A insustentabilidade global trouxe consigo os refugiados: políticos, de guerras e de catástrofes ambientais, gerando a necessidade de locais específicos para o abrigo desta população na forma de acampamentos temporários planejados. São estruturas provisórias dotadas de mobiliários que por sua vez possuem características específicas para este uso. Estando sujeitos às condições ambientais e de uso intenso, os materiais usados devem ser leves, de fácil montagem, com baixo impacto ambiental e baixo custo. Este artigo contribui para a sistematização de informações a serem disponibilizadas em uma plataforma denominada Infrashelter, voltada à catalogação de estruturas para acampamentos planejados e particularmente, dos mobiliários e materiais utilizados nestas estruturas. Como resultado parcial da pesquisa, propõe-se a estrutura de catalogação que permita a identificação dos mobiliários presentes nos acampamentos, seus materiais constituintes e principais características que possam ser utilizadas como referências de projetos.

\section{ABSTRACT}

Furniture is characteristic of human civilization and has been used more than 15,000 years ago, having different characteristics depending on use. Global unsustainability brought refugees: politicians, wars and environmental catastrophes, creating a need for specific places to shelter this 


\section{GESTÃO \& SUSTENTABILIDADE} AMBIENTAL

\section{¿unisul}

population as temporary planned camps. They are provisional structures with especific furniture, ture. Being subject to environmental conditions and intense use, the materials used must be light, easy to assemble, using materials with low environmental impact and low cost, among other characteristics. This paper contributes to the systematization of information to be made available on a platform called Infrashelter, aimed at cataloging structures for planned camps, and particularly, the furniture and materials used in these structures. As a partial result of the research a cataloging structure is proposed, which allows the identification of the furniture present in them, their constituent materials and main characteristics that can be used as project references. 


\section{INTRODUÇÃO}

A ocorrência de crises humanitárias, sejam por consequência de desastres naturais e/ou por influência humana, ou de emergências humanitárias complexas, traz a necessidade do estabelecimento de planos emergenciais, que visam urgente restauração, estabelecendo acampamentos provisórios de forma rápida, para abrigar e abastecer as populações afetadas. Segundo Carbonari (2021), essas ocorrências evidenciam a necessidade do desenvolvimento de estudos referentes ao planejamento e projeto de abrigos temporários para a população desabrigada, com o objetivo de preparar profissionais para atuarem na resposta humanitária.

Em conjunto a isso, conforme a Sphere Association (2018), uma resposta humanitária eficaz deve fazer uma avaliação cuidadosa do risco ambiental em conjunto a outras análises mais amplas e a uma análise situacional. Além disso, deve minimizar o impacto ambiental e considerar como as questões de aquisição, transporte, escolha de materiais, terreno e o uso dos recursos naturais, podem proteger ou degradar ainda mais o meio ambiente. Portanto, é indispensável inserir as questões de sustentabilidade no processo de planejamento e projeto de abrigos.

Valencio, Marchezini e Siena (2008) apontam três desafios fundamentais para a provisão de abrigos temporários no que se refere à disponibilização das condições materiais, na forma de espaço físico apropriado, recursos humanos capacitados e bens de forma a assegurar o mínimo necessário para satisfazer as necessidades dos usuários no momento em que essas se manifestam.

\section{¿unisul}

Uma das questões relacionadas à infraestrutura é a providenciar o mobiliário para atender à todas as atividades necessárias nos acampamentos: atendimento à saúde, guarda e proteção de bens, descanso, lazer, coleta de resíduos, preparo de alimentos e alimentação, enfim, de forma a permitir que as necessidades dos usuários sejam atendidas.

Como foco do artigo, os mobiliários para arquitetura emergencial são de extrema importância para o funcionamento do abrigo, pois propiciam a utilização e apropriação do espaço. Entretanto, existe uma dificuldade das escolhas dos materiais pelos projetistas, e atrelado às questões de sustentabilidade, se faz necessário o estabelecimento de referenciais disponibilizados de maneira acessível e que facilitem a inserção de novas informações, como apoio à decisão em projetos de arquitetura emergencial.

O presente artigo abordará a sistematização de informações a serem utilizadas na catalogação de mobiliários e materiais que compõem os acampamentos planejados. O resultado será disponibilizado no site da Materioteca Sustentável

(https://materioteca.paginas.ufsc.br/), e futuramente comporá uma plataforma denominada Infrashelter, voltada à catalogação de estruturas para acampamentos planejado, nesse caso particular dos mobiliários e materiais que compõem as estruturas. Como resultado parcial, propõe-se a estrutura de catalogação que permita a identificação dos mobiliários presentes nos acampamentos, seus materiais constituintes e principais características que possam ser utilizadas como referências de projetos. Ainda, apresenta-se a proposta da utilização de um método para a avaliação dos materiais dos 
mobiliários para acampamentos planejados, visando as questões econômicas, sociais e ambientais em conjunto com uma lista preliminar de acampamentos planejados internacionais e nacionais. Nos componentes dessa lista, realizou-se a análise de alguns espaços, demonstrando-se a estrutura de catalogação para um dos casos selecionados, o acampamento de Zaatari. Por fim, apresenta-se ainda uma proposição de catalogação dos mobiliários e seus materiais relacionados aos dados associados ao acampamento, a serem utilizados na futura Plataforma Infrashelter, contribuindo para o estabelecimento de referenciais.

\section{MÉTODOS, ETAPAS E TÉCNICAS}

Este artigo apresenta parte de uma pesquisa em desenvolvimento sobre o estudo de materiais e sustentabilidade, com foco em mobiliários para acampamentos planejados, que apresenta as seguintes etapas vistas na Figura 1, estando situado na terceira etapa.

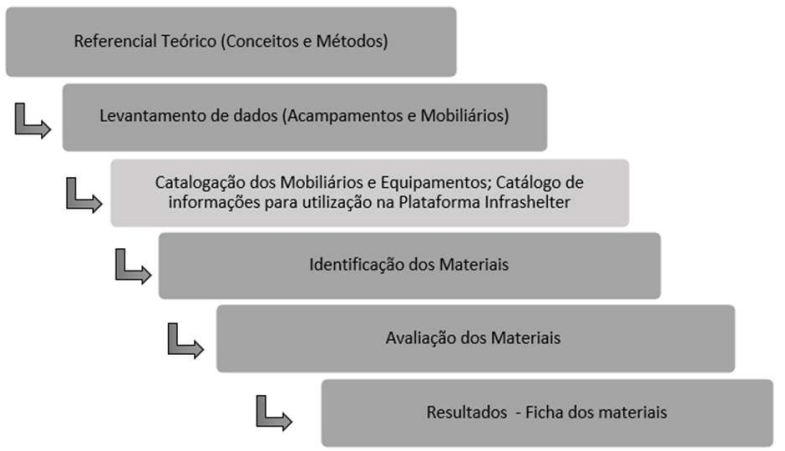

Figura 1 - Principais etapas da pesquisa. Fonte: elaborado pelos autores.

Neste artigo, propõe-se a classificação de mobiliários para acampamentos planejados, e para esse objetivo, realizou-se uma revisão bibliográfica como forma de fundamentar a proposta. Com base nesta, abordou-se os conceitos da definição das etapas na provisão

\section{ounisul}

de abrigo e habitação para cenários de emergência, conceituou-se as características dos mobiliários para arquitetura emergencial, apresentou-se a classificação dos mobiliários conforme seu uso de Ferroli et al. (2019), e a classificação dos materiais de Ferroli et al. (2017), para facilitar o processo de seleção.

Como resultados parciais desta pesquisa, realizou-se uma análise de mobiliários necessários em uma arquitetura de caráter emergencial, com base na estrutura de indicadores estabelecida por Carbonari (2021). Apresentou-se a proposta da inserção do método ESA-mod apresentado por Librelotto et al. (2012), para avaliação dos materiais, levando em consideração os critérios econômicos, sociais e ambientais. Além disso, realizou-se a seleção de acampamentos planejados, brasileiros e internacionais. Como critério, estabeleceu-se uma linha temporal de 2010-2021. Demonstrou-se a aplicação da proposta de catalogação dos mobiliários para acampamentos planejados, de forma exploratória, pois optou-se por um método de classificação dos materiais a partir de uma identificação preliminar. A identificação aprofundada será realizada em uma etapa posterior, como visto na Figura 1. Para essa aplicação da proposta, utilizou-se um dos casos selecionados anteriormente, o acampamento de Zaatari, na Jordânia. Por fim, apresentou-se uma proposição de catalogação dos mobiliários e seus materiais relacionados aos dados associados ao acampamento, a serem inseridos na futura Plataforma Infrashelter.

\section{REFERENCIAL TEÓRICO}

\subsection{Conceitos sobre acampamentos planejados}


Quarantelli (1991) apresenta a definição de quatro tipologias que consideram diferenciações entre abrigos e habitações para cenários de emergência, sendo elas: abrigos emergenciais, abrigos temporários, habitação temporária e habitação permanente. Os abrigos emergenciais possuem curta duração, horas ou até dias, necessitando de pouca infraestrutura e serviços. Ainda podem se utilizar de estruturas fixas preexistentes ou serem instalados em estruturas construídas para este fim exclusivo, normalmente na forma de acampamentos planejados. Por conta de sua curta duração, as condições aceitas nem sempre são as ideais, geralmente usando ambientes como igrejas, escolas ou estádios. Os abrigos temporários, possuem duração de dias a meses, envolvendo a necessidade de mais infraestrutura e serviços. Nos abrigos, não há a tentativa de restabelecer a rotina do lugar, sendo o objetivo principal o retorno dos desabrigados a suas respectivas residências. Já as habitações se caracterizam por apresentar a retomada da rotina e das atividades diárias. A habitação temporária geralmente se estende por meses a anos. E por fim, a habitação permanente, referindo-se ao retorno dos desabrigados para suas casas reconstruídas ou reparadas, ou em reassentamentos.

Carbonari (2021), em sua tese de doutorado, faz uma tentativa de categorização dos conceitos encontrados na bibliografia internacional e nacional. Os conceitos estão esquematizados na Figura 2.

\section{¿Unisul}

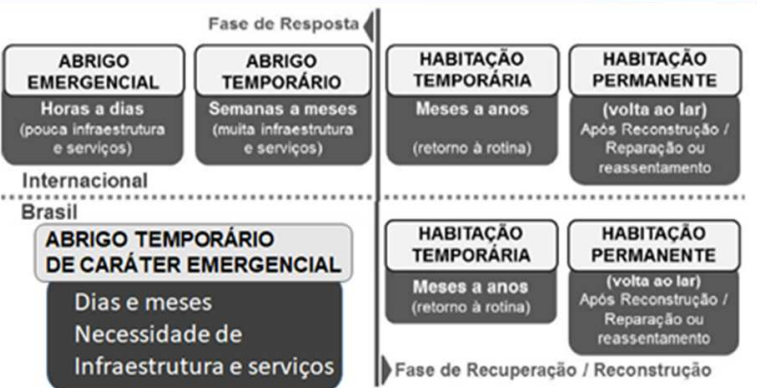

Figura 2 - Principais conceitos. Fonte adaptada: Carbonari (2021).

Ainda, de acordo com Corsellis e Vitale (2005) os abrigos transitórios (transitional settlement) classificam-se em seis tipos, divididos em duas soluções: dispersas e agrupadas. Entre as soluções agrupadas estão os acampamentos planejados, caracterizando-se pela escolha de um local que apresenta a infraestrutura e os serviços necessários.

Com base na conceituação dos tipos de abrigos, é possível entender que a classificação diz muito sobre as características dos mesmos. Nota-se que a maioria dos abrigos, emergenciais e temporários, surgem da necessidade urgente de recuperação, estabelecendo acampamentos provisórios para abrigar e abastecer as populações afetadas. Segundo Moreno-Sierra et al. (2020), a maioria desses abrigos, é fornecida por organizações internacionais, constituindo-se em um agrupamento de tendas provisórias de tecido, estruturas leves pré-fabricadas, que são erguidas em um curto espaço de tempo, e geralmente projetadas para não durar. É importante considerar que muitos abrigos temporários extrapolam o seu tempo de duração previsto, e a ausência de um planejamento pode prejudicar a permanência dos usuários. 


\section{sunisul}

A ausência de planejamento se estende aos mobiliários nesses abrigos. Os móveis são elementos de extrema importância, não só em consideração ao conforto e usabilidade, mas também possibilitando uma função importante de apropriação do espaço e realização das atividades necessárias.

\subsection{Mobiliários e equipamentos em arquitetura emergencial e acampamentos planejados}

Pascucci (2021) fez um estudo sobre a questão da gestão da logística humanitária em situações pós-desastres nos abrigos conhecidos como RHU - Refugee Housing Unit - pela empresa Better Shelter. Foram distribuídas mais de 30.000 unidades da Better Shelter para acampamentos planejados ao redor do mundo, do Peru à Indonésia, incluindo o Brasil (nos acampamentos para refugiados Venezuelanos) da Operação Acolhida do exército brasileiro.

Estas unidades da Better Shelter foram contempladas com um prêmio de design, que segundo Pascucci (2021), foi atribuído em função de que o novo produto proporciona "lares seguros" para pessoas deslocadas em todo o mundo, utilizando uma tecnologia flatpack no design do mobiliário para criar um abrigo que pode ser facilmente montado e transportado. De acordo com o autor, as unidades de 17 metros quadrados são transportadas em kits compostos por duas caixas com todas as ferramentas necessárias que pode ser montado em até duas horas.

Apesar das unidades Better Shelter serem bastante controversas pelo seus uso indiscrimado, independente do clima e da cultura local, a facillidade de montagem e transporte, sem dúvida, são fatores que justificam o seu sucesso. A Figura 3 mostra a imagem de uma unidade Better Shelter em kits e montada e com a ocupação de usuários.

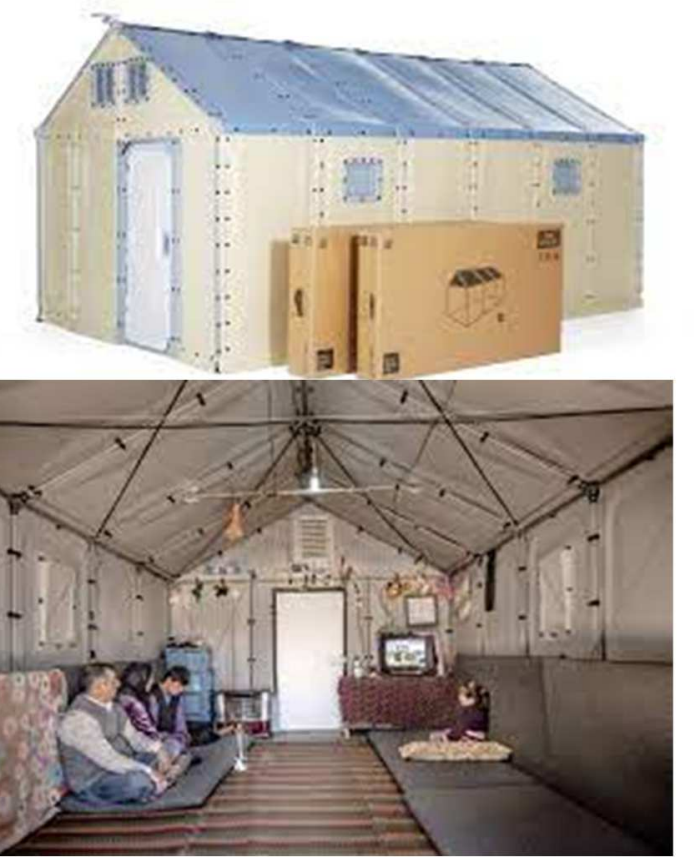

Figura 3 - Unidade Better Shelter - caixas e formas de ocupação. Fonte adaptada: Better Shelter (2021).

No caso em destaque, ressalta-se que qualquer projetista deveria saber que um produto de sucesso necessita ser facilmente transportado e deve caber em um navio. Esta realidade atinge em cheio as questões associadas aos ditos "bens humanitários", nos quais estão incluídos os mobiliários e toda a sua cadeia produtiva.

Mook et al. destacam a importância do mobiliário nas situações emergenciais de logística humanitária e a partir do relato de abrigos onde as pessoas eram alojadas no chão ou sem qualquer tipo mobiliário, estudaram a estratégia da criação do Furniture Bank, um espaço de trocas de mobiliária, enfatizando uma outra característica que deve estar presente: a possibilidade de reaproveitamento.

Os mobiliários para arquitetura emergencial possuem características distintas dos outros tipos de mobiliários. Monteiro (2017) faz uma 
comparação entre o design do mercado e o design social, onde o objetivo do design para o mercado é criar produtos que tenham como foco a sua venda e promoção, já o design social tem o objetivo primordial de satisfazer as necessidades humanas. Essa distinção traz como principais diferenças a mobilidade e os materiais empregados nesse tipo de mobiliário.

Datta (2005) fez um estudo em diversas unidades de abrigos emergenciais no Arizona. A autora destaca a participação do mobiliário na organização do espaços, muitas vezes sendo utilizado como um elemento de delimitação e também de apropriação do espaço.

Segundo Feres (2014), no momento de projeto dos abrigos, os materiais a serem utilizados, além de serem familiares, respeitando o aspecto cultural, devem ser coerentes aos recursos disponíveis, e resistentes, com durabilidade conforme o tempo estimado de uso dos abrigos. Face a isso, relaciona-se alguns desses fatores particulares dos abrigos em acampamentos planejados, para os mobiliários que estarão neste espaço.

Portanto, conforme as condições em que os mobiliários estarão sujeitos, seleciona-se algumas condicionantes a serem consideradas no momento do projeto, como a composição dos materiais usados os quais devem ser leves, de fácil montagem, utilizando materiais de baixo impacto ambiental, de baixo custo, com durabilidade conforme o reuso, com ampla disponibilidade local, considerando os aspectos culturais dos usuários e a flexibilidade do mobiliário, que poderá desempenhar diversos usos em um único objeto. Além dos mobiliários, é importante considerar a necessidade de equipamentos para a habitabilidade dos usuários nos acampamentos planejados. Estes podendo ser

\section{¿Unisul}

adquiridos prontos, ou produzidos, possibilitando montagem e desmontagem no local.

\subsection{Indicadores de implantação e projeto de acampamentos planejados}

Considerando a necessidade do desenvolvimento de estudos referentes ao planejamento e projeto de abrigos temporários, no Quadro 1 são apresentadas as estruturas hierárquicas com os critérios e subcritérios, divididas em duas hierarquias: seleção do local e projeto de acampamentos temporários planejados, de acordo com Carbonari (2021).

Baseando-se nesses critérios e subcritérios de Carbonari (2021), posteriormente serão estabelecidos o catálogo dos mobiliários e equipamentos necessários para acampamentos planejados e a sistematização de informações a serem utilizadas na futura Plataforma Infrashelter. 


\section{১unisul}

Quadro 1 - Indicadores de implantação e projeto de acampamentos planejados. Fonte: elaborado pelos autores com base em Carbonari (2021)

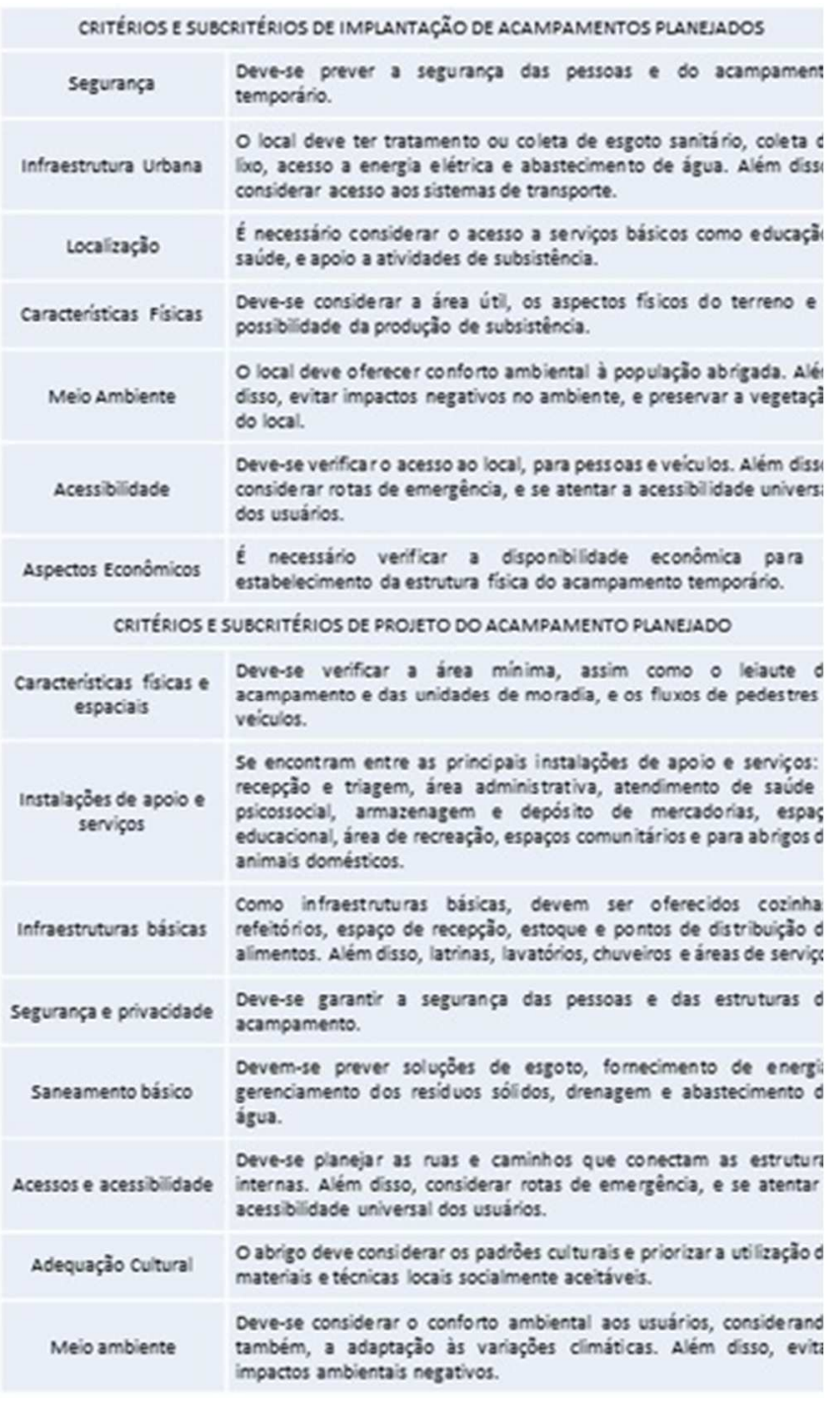

\subsection{Classificação dos mobiliários}

Ferroli et al. (2019), apresenta uma classificação dos mobiliários, onde estes são identificados conforme sua utilização, nas seguintes categorias:

(1) Mobiliário residencial, projetado para uso interno, com poucos usuários (em geral núcleo familiar e convidados), com ambiente não agressivo e pouco sujeito a intempéries.
(2) Mobiliário condominial interno, projetado para uso interno, mas com muitos usuários (pousadas, escolas, restaurantes, etc.). O ambiente não é tão agressivo, pouco sujeito a intempéries, porém o material está mais sujeito ao desgaste pelo uso compartilhado e mais intenso.

(3) Mobiliário condominial externo, projetado para uso externo, com muitos usuários, em ambiente com público controlado (varandas, decks, sacadas, etc.). Com ambiente agressivo, sujeito a intempéries e desgaste pelo uso compartilhado e intenso.

(4) Mobiliário urbano, projetado para uso externo, com muitos usuários, em ambientes com público de livre acesso (praças, passarelas, pontes, estacionamentos, etc.). Ambiente agressivo, sujeito a intempéries e possibilidade de vandalismo, com uso intenso.

Visto as diferentes características dos mobiliários para arquitetura emergencial, em relação aos outros tipos de mobiliários, a partir dessa classificação já existente, será adicionado uma nova categoria específica para estas situaçõos.

\subsection{Classificação dos materiais}

O estudo dos materiais é fundamental para o projetista. Conforme Calegari e Oliveira (2014), "os materiais desempenham papel essencial no processo de concepção dos produtos, pois concretizam as ideias, os conceitos e desenhos criados pelos designers." Os materiais presentes nos produtos trazem consigo percepções ao usuário. Para Dias (2009), “[...] a experiência dos usuários tem papel preponderante nesse momento, uma vez que, ao interagirem com o produto, estabelecem relações sensoriais (táteis, visuais, 


\section{ounisul}

auditivas, olfativas ou gustativas) que podem ser determinantes em sua concepção."

Para Ashby e Johnson (2010) a materialidade concebe a personalidade de um produto, pois um material possui particularidades percebidas ou associações que os adquire quando utilizado no mesmo. Contudo, a cada dia que passa a ciência e a tecnologia avançam de forma progressiva, ocasionando o surgimento de diversos novos materiais. Segundo Callister (2000), os primeiros seres humanos tiveram acesso a um número limitado de materiais, e com o tempo, foram descobrindo técnicas para a produção de novos materiais. E com o surgimento de novos materiais, atrelaram-se novas questões, conforme exposto por Dias (2009), "uma das dificuldades encontradas pelos designers e que, de certa forma, interfere na comunicação dos produtos, é que está cada vez mais difícil classificar os materiais em categorias simples e definitivas, em razão de sua diversidade e hibridez."

Portanto, percebendo-se a complexidade das classificações apresentadas por autores, optouse para a pesquisa o uso da classificação de Ferroli et al. (2017), apresentando uma listagem classificatória de materiais, com o objetivo de facilitar o processo de seleção. Atualmente conta com 17 quadros, apresentados na Figura 4.

Esses quadros podem ser encontrados no site da Materioteca Sustentável (https://materioteca.paginas.ufsc.br/), ainda, direcionando para classificação em grupos, subgrupos e tipos, que contribuirão para identificação dos materiais dos mobiliários posteriormente.

\begin{tabular}{|c|c|}
\hline Quadro 1 & Madeiras naturais, transformadas e para revestimentos \\
\hline Quadro 2 & Papêis (comum), cartốes e papelâo \\
\hline Quadro 3 & Metais ferrosos (aços e ferros fundidos) \\
\hline Quadro 4 & Metais nāo-ferrosos (ligas) \\
\hline Quadro 5 & Materiais sinterizados - Metalurgia do pó \\
\hline Quadro 6 & $\begin{array}{l}\text { Polimeros-plasticos (commodities, de engenharia, de alta } \\
\text { performance) }\end{array}$ \\
\hline Quadro 7 & Polimeros - blendas \\
\hline Quadro 8 & Polímeros - adesivos \\
\hline Quactro 9 & Cimentos, concretos $\mathrm{e}$ agregados \\
\hline Quadro 10 & Ceràmicas (comuns) e Vidros \\
\hline Quadro 11 & Materiais naturais (bambu, gemas, pedras, couro, lik. e outros) \\
\hline Quadro 12 & Fibras naturais (rami, sisal, juta, côco, etc.) e fibras artifficiais \\
\hline Quadro 13 & Borrachas naturais e sintéticas \\
\hline Quadro 14 & Oleos e graxas \\
\hline Quadro 15 & Tintas e vernizes \\
\hline Quadro 16 & Materiais de nano tecnologia \\
\hline Quadro 17 & Compositos avançados \\
\hline
\end{tabular}

Figura 4 - Classificação de materiais. Fonte: Materioteca Sustentável (2021).

\section{RESULTADOS PARCIAIS}

\subsection{Tipos de mobiliários e equipamentos para arquitetura emergencial}

Com base nos critérios e subcritérios de Carbonari (2021), apresentados no Quadro 1, determinou-se os mobiliários e equipamentos necessários para acampamentos planejados, conforme o Quadro 2.

\subsection{Proposta de Classificação dos Mobiliários}

Este tópico apresentará a proposta de um método para avaliação dos materiais presentes nos mobiliários. No entanto, o primeiro passo será a classificação do mobiliário referente a sua utilização. Observando a classificação dos mobiliários realizada por Ferroli et al. (2017), percebe-se que não há uma categoria que se adeque às características dos mobiliários 


\section{¿UNISUl Gimat}

presentes nos acampamentos planejados, assim, insere-se nessa classificação já existente, uma nova categoria (Mobiliário para arquitetura emergencial) para estes casos específicos, conforme demonstrado na Figura 4.

Quadro 2 - Mobiliários e equipamentos necessários. Fonte: elaborado pelos autores.

\begin{tabular}{|c|c|c|}
\hline \multicolumn{3}{|c|}{ Mobiliários e equipam entos necessários para a campamentos planejados } \\
\hline $\begin{array}{c}\text { Critérios de } \\
\text { Carbonari (2021) }\end{array}$ & Espaços & Mobiliários e Equipamentos \\
\hline \multirow[b]{4}{*}{$\begin{array}{l}\text { Inf raestrutura } \\
\text { Urbana }\end{array}$} & Coleta de lixo & Contentores de lixo. \\
\hline & Energia & Equip amento de captação de energia solar. \\
\hline & Água & Reservatório. \\
\hline & $\begin{array}{l}\text { Nos sistemas de } \\
\text { transporte urbano } \\
\text { próximos aos } \\
\text { acampamentos }\end{array}$ & $\begin{array}{l}\text { Bancos, abrigos para embarque, totens } \\
\text { informacionais, sistemas de iluminação (post } \\
\text { luminárias, e etc), sistemas de comunicação } \\
\text { fornecimento de energia (por exemplo, } \\
\text { carregamento de celulares). }\end{array}$ \\
\hline Acessibilidade & Acesso a local & Rampas, guarda-corpo. \\
\hline \multirow{6}{*}{$\begin{array}{l}\text { Caracteristicas } \\
\text { fisicas e espaciais }\end{array}$} & & Para salas: \\
\hline & & $\begin{array}{l}\text { Sofäs, Racks e Estantes, Painèis de TV, Poltri } \\
\text { mesas de centro, puffs, aparadores, pratelei } \\
\text { nichos. }\end{array}$ \\
\hline & & Para quartos: \\
\hline & $\begin{array}{l}\text { Área das unidades de } \\
\text { moradia }\end{array}$ & $\begin{array}{l}\text { Armários, baús, colchões, cômodas, mesas d } \\
\text { cabeceira, camas tradicionais (solteiro, casal, } \\
\text { beliches, treliches, quadriliches, sofás cama, } \\
\text { sapateiras, estantes, prateleiras, guarda-roupz } \\
\text { penteadeiras. }\end{array}$ \\
\hline & Recepção e triagem & Mesas, cadeiras, armários, luminárias. \\
\hline & Área administrativa & $\begin{array}{l}\text { Mesas, cadeiras, armários, arquivos, bancos, } \\
\text { sofás. }\end{array}$ \\
\hline \multirow{3}{*}{$\begin{array}{l}\text { Instala ções de apoio } \\
\text { e serviços }\end{array}$} & Psicossocial & Mesas e cadeiras. \\
\hline & Cuidados com saúde & Mesas cadeiras, biombos e macas fixas. \\
\hline & $\begin{array}{l}\text { Armazenagem e } \\
\text { depósito de }\end{array}$ & Estantes, armários, nichos. \\
\hline
\end{tabular}

Após a classificação do tipo de mobiliário, referente a sua utilização, foram adotados critérios para avaliação do material dos mobiliários, com base em fatores econômicos, sociais e ambientais. As questões adotadas para a classificação dos materiais foram originados do modelo ESA-mod apresentado em Librelotto, et al (2012), adaptado de Librelotto (2005), e são elas: Preço de Aquisição , Quantidade de material utilizado, Tempo de fabricação, Quantidade dos fornecedores locais, Disponibilidade local, Durabilidade, Reciclabilidade, Biodegradabilidade e Emissão de $\mathrm{CO}^{2}$. Essas nove condicionantes adotadas, foram selecionadas com base em sua utilização já existente para a avaliação dos materiais realizados nas fichas de cada material da Materioteca Sustentável (https://materioteca.paginas.ufsc.br/).

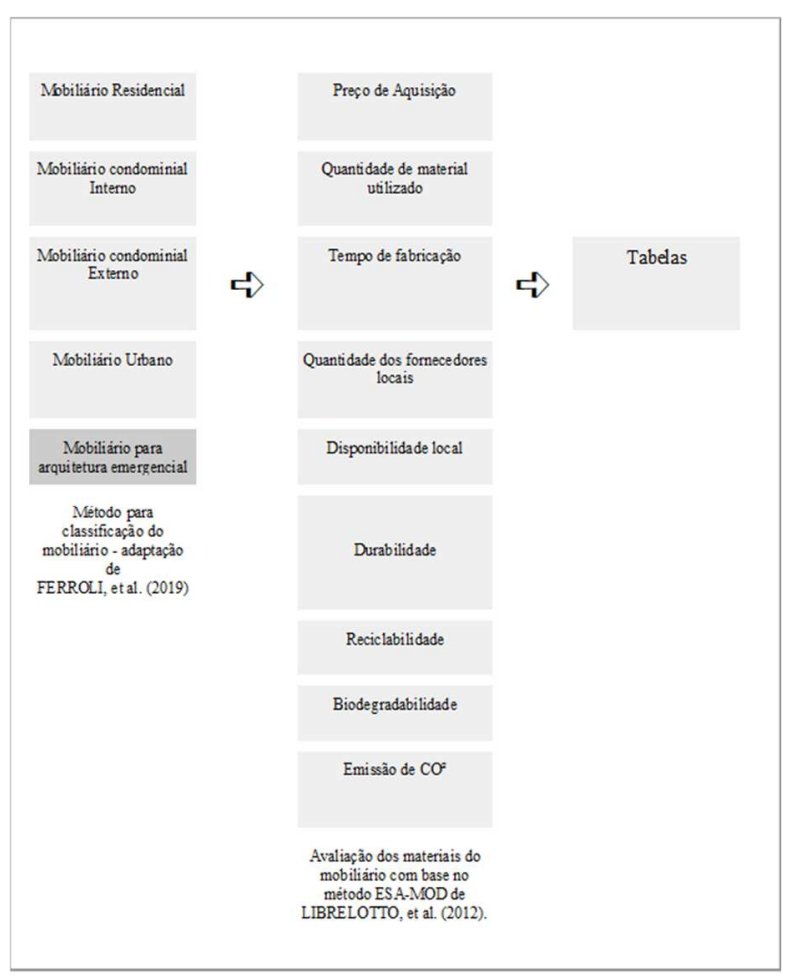

Figura 5 - Proposta de classificação e avaliação dos mobiliários. Fonte: elaborado pelos autores

\subsection{Lista de acampamentos planejados}

Com o intuito de analisar os mobiliários em acampamentos planejados, resultados de eventos de desastres naturais e conflitos, estabeleceu-se um período de 10 anos, entre 
2010 e 2021, no Brasil e no mundo. Assim, selecionou-se alguns acampamentos que teriam potencial analisado.

\subsubsection{Acampamentos brasileiros}

Os acampamentos brasileiros fornecem proteção para refugiados, principalmente vindos da Venezuela (Carbonari, 2021), e para vítimas de desastres naturais, sendo mais frequentes no país as inundações (EM-DAT, c2020). Os acampamentos selecionados são:

- acampamentos que acolhem refugiados venezuelanos: Pintolândia, Tancredo Neves, Jardim Floresta, Nova Canaã, Santa Teresa, Hélio Campos, Latife Salomão, São Vicente e Rondon I,

- $\quad$ abrigos instalados para os desabrigados resultante da quebra das barragens em Mariana e em Brumadinho, $\mathrm{MG}$ e

- Inundações ocorridas na região Serrana do Rio de Janeiro, nas cidades de São José do Rio Preto, Teresópolis, Nova Friburgo, Bom Jardim, Petrópolis, Sumidouro, Areal.

\subsubsection{Acampamentos internacionais}

Em âmbito mundial, os principais acampamentos planejados abrigam os refugiados de alguns países da Ásia e da África (ACNUR-BRASIL, c2021), assim como, em termos de desastres naturais, as regiões mais afetadas se localizam próximas à costa do pacífico e do oceano Índico. Os principais acampamentos que acolhem refugiados são:

- Duzce na Turquia,

- Zaatari na Jordânia,

- Azraq na Jordânia,

- $\quad$ Ajuong Thok no Sudão,

\section{sunisul}

- Dadaab em Kenya,

- $\quad$ Bentiu no Sudão do Sul e

- $\quad$ Férério em Burkina Faso.

Já os acampamentos que foram selecionados abrigaram as vítimas dos seguintes desastres naturais:

- $\quad$ Terremoto no Haiti em 2010,

- $\quad$ Terremoto no Nepal em 2015,

- Tufâo Haiyan (Yolanda) nas Filipinas em 2013 na comunidade de Sungko e na cidade de Tacloban,

- $\quad$ Tsunami no Japão em 2011,

- $\quad$ Terremoto no Equador em 2016 nas províncias de Manabí e Esmeraldas,

- $\quad$ Deslizamento de terra do Peru em 2012

- Ciclone Evans na Ilha de Samoa em 2012

\subsection{Aplicação da proposta de catalogação de mobiliários para acampamentos planejados - caso Zaatari}

Como parte do resultado parcial da pesquisa, propõe-se a utilização da estrutura de catalogação já exposta, onde é realizada a identificação dos mobiliários presentes para alguns espaços identificados, seus materiais constituintes e principais características que possam ser utilizadas como referências de projetos. Os materiais identificados serão associados aos quadros de classificação dos materiais, linkados as fichas presentes no site da Materioteca Sustentável (https://materioteca.paginas.ufsc.br/) e avaliados conforme os itens apresentados na Figura 4. 


\section{GESTÃO \& SUSTENTABILIDADE AMBIENTAL

\section{¿Unisul}

Para a demonstração da utilização da proposta de catalogação dos mobiliários e equipamentos, será utilizado um dos acampamentos listados no tópico 4.3, o caso do acampamento Zaatari, na Jordânia. O Quadro quantidade de fornecedores locais, biodegradabilidade, emissões de $\mathrm{CO}_{2}$, só poderão ser realizados mediante determinação precisa do tipo de material, o que deve ser realizado em um segundo momento desta

Quadro 3 - Análise dos mobiliários e equipamentos Fonte: elaborado pelos autores

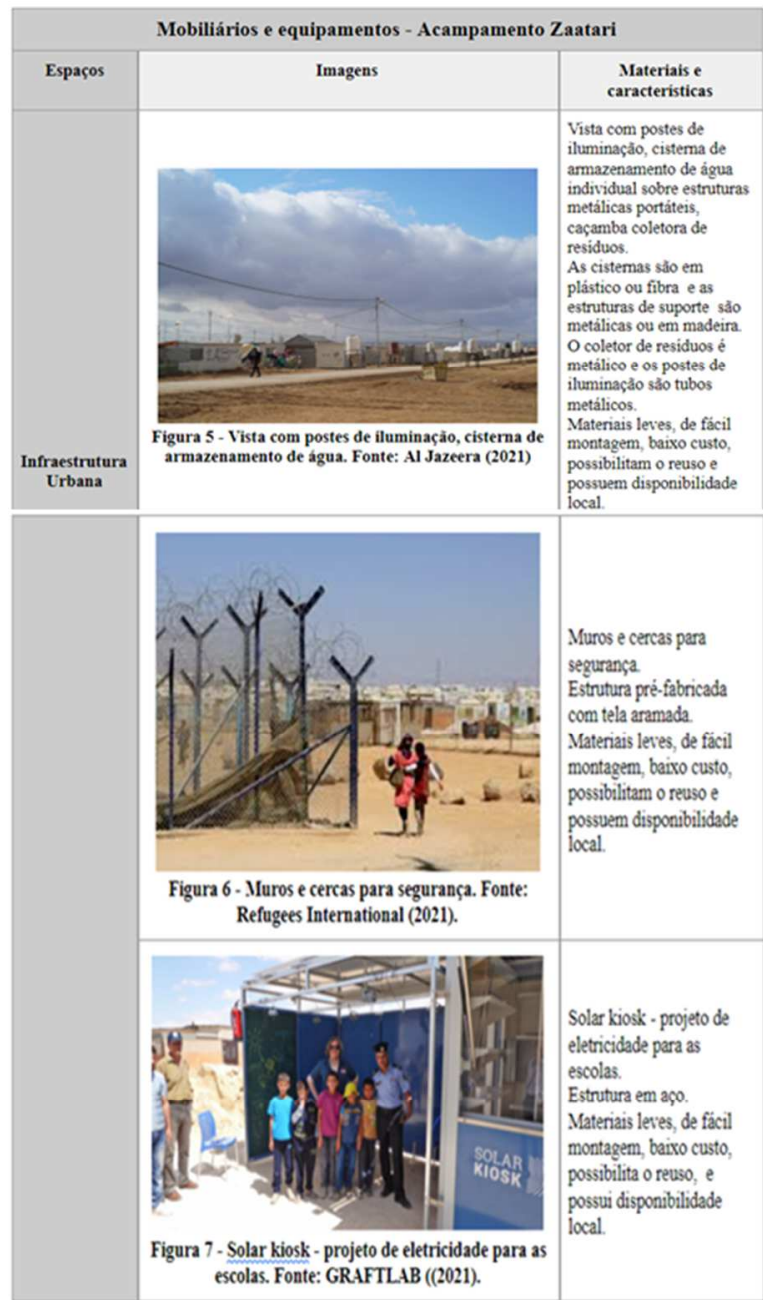

3 apresenta a identificação de mobiliários e equipamentos presentes no acampamento planejado, uma identificação exploratória dos materiais utilizados nestes e avaliação qualitativa quanto aos aspectos de uso e função, facilidade de montagem, custo $\mathrm{e}$ disponibilidade. Os demais aspectos como

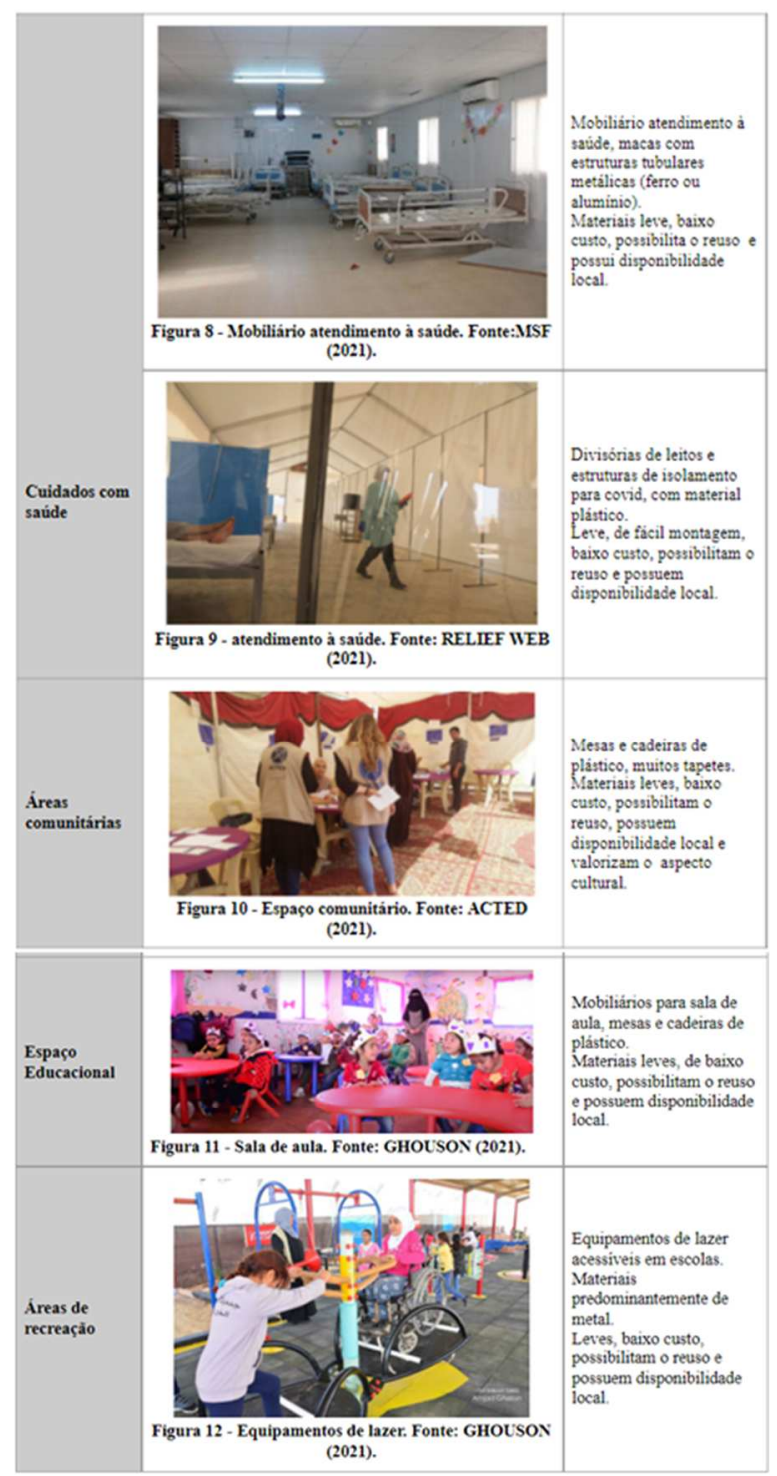

pesquisa.

Com base nos critérios de Carbonari (2021) e na análise realizada, determinou-se um catálogo de mobiliários e seus materiais (Quadro 4) que devem ser analisados nos 
acampamentos planejados, e os dados levantados serão associados ao acampamento na futura Plataforma Infrashelter.

Quadro 4 - Catalogação dos mobiliários e equipamentos. Fonte: elaborado pelos autores.

\begin{tabular}{|c|c|}
\hline \multicolumn{2}{|c|}{ CATÁLOGO DE MOBILIÁRIOS EM ACAMPAMENTOS PLANEJADOS } \\
\hline Emergência (Emergency) & Emergência ocorrida, como conflito ou desastre. \\
\hline Localização (Localization) & Local onde se encontra 0 acampamento. \\
\hline $\begin{array}{l}\text { Estrutura do acampamento } \\
\text { (Camp stricture) }\end{array}$ & $\begin{array}{l}\text { A estrutura do acampamento, ou seja, suas partes, como } \\
\text { cozinhas, areas comunitárias, espaços recreativos, leiaute, } \\
\text { entre outros. Esta estrutura deverá seguir o que foi } \\
\text { estabelecido no Quadro 2, quanto aos espaços e as estruturas. }\end{array}$ \\
\hline $\begin{array}{l}\text { Ser viços bá sicos do } \\
\text { acamp amento e acessos } \\
\text { (Canp basic services and } \\
\text { access) }\end{array}$ & $\begin{array}{l}\text { Infraestruturas presentes nos acampamentos, como os acessos } \\
\text { ao local, sistemas de saneamento e serviços básicos. Esta } \\
\text { estrutura deverá seguir o que foi estabelecido no Quadro 2, } \\
\text { quanto aos espaços e as estruturas. }\end{array}$ \\
\hline Espaço (Space) & $\begin{array}{l}\text { Defini ção da função de cada espaço na estrutura. Exemplo: } \\
\text { ESCOLA, playground. }\end{array}$ \\
\hline Mobiliário (Furniture) & $\begin{array}{l}\text { Função do equipamento descrito. Exemplo: Brinquedo - } \\
\text { gangorra. }\end{array}$ \\
\hline Custo (Cust) & Custo de implantação do acampamento e dos abrigos. \\
\hline $\begin{array}{l}\text { Especificações do mobiliário } \\
\text { (Furniture specifications) }\end{array}$ & $\begin{array}{c}\text { Descreve-se a composição, materiais utilizados e dimensões, } \\
\text { entre outros. }\end{array}$ \\
\hline $\begin{array}{l}\text { Cla ssificação do material } \\
\text { (Material classification) }\end{array}$ & Tipo material, link para fichas da materioteca. \\
\hline Avaliação (Assessment) & Conforme os requi sitos estabelecidos na figura 3. \\
\hline $\begin{array}{l}\text { Imagens e desenhos (Images } \\
\text { and drauings) }\end{array}$ & $\begin{array}{c}\text { Imagens, model os e desenhos técnicos que ilustram o } \\
\text { mobiliârio utilizado. }\end{array}$ \\
\hline Publicações (Publications) & As principais publicações sobre 0 acampamento. \\
\hline
\end{tabular}

\section{CONSIDERAÇÕES FINAIS}

Este artigo teve por finalidade contribuir para a sistematização de informações a serem disponibilizadas no site da Materioteca Sustentável (https://materioteca.paginas.ufsc.br/) $\mathrm{e}$ posteriormente em uma plataforma denominada Infrashelter, desenvolvendo catalogação de estruturas para acampamentos planejados, com foco para os mobiliários e materiais utilizados nestas. Demonstrou-se inicialmente a conceituação dos tipos de abrigo e habitação para cenários de emergência. Considerou-se a classificação dos mobiliários em residencial, condominial interno, condominial externo, urbano, e propôs-se a criação de uma nova categoria voltada especificamente para arquitetura emergencial.

\section{ounisul}

Apresentou-se a importância dos materiais na concepção do produto, e sua classificação baseando-se em autores.

Com base no referencial teórico, propôs-se a utilização de um método de avaliação dos materiais de mobiliário e se desenvolveu uma estrutura de catalogação, permitindo a identificação dos mobiliários presentes nestas, seus materiais constituintes e principais características que possam ser utilizadas como referências de projetos.

Desta maneira, levando-se em conta diversos fatores associados às suas características distintas, pretende-se auxiliar o projetista na escolha de seus materiais de forma a contribuir para a proposição de escolhas mais interessantes, que inserem como premissa a tríade econômica, social e ambiental, tendo com base a catalogação de referenciais de projeto

\section{REFERÊNCIAS}

ACNUR-BRASIL. ACNUR. c2021.

Disponível em:
https://www.acnur.org/portugues/. Acesso em: 06 jan. 2021.

ACTED. First Job en Zaatari Refugee Camp. Disponível em: $<$ https://www.acted.org/en/first-job-fair-inzaatari-refugee-camp/>. Acesso em: 2021.

ASHBY, M. F.; JOHNSON, K. Materials and design: the art and science of material selection in product design. Amsterdam: Elsevier/ButterworthHeinemann, 2010.

AL JAZEERA. Syria's War: Zaatari Camp.
Disponível em
<https://www.aljazeera.com/gallery/2018/4/1/




\section{DUNISUI}

syrias-war-inside-jordans-zaatari-refugee-

camp>. Acesso em: 2021.

BETTER SHELTER. Disponível em: <better shelter.org>. Acesso: Julho de 2021.

CALEGARI, Eliana Paula; DE OLIVEIRA, Branca Freitas. Aspectos que influenciam a seleção de materiais no processo de design. Arcos Design, v. 8, n. 1, p. 1-19, 2014.

CALLISTER, William. Ciência e Engenharia de Materiais: Uma Introdução. Grupo GenLTC, 2000.

CARBONARI, Luana Toralles. Modelo multicritério de decisão para o projeto de acampamentos temporários planejados voltados a cenários de desastre. 2020. $409 \mathrm{f}$. Tese (Doutorado) - Curso de Arquitetura e Urbanismo, Universidade Federal de Santa Catarina, Florianópolis, 2021.

DIAS, Maria Regina Álvares Correia. Percepção dos materiais pelos usuários: modelo de avaliação Permatus. 2009. $368 \mathrm{f}$. Tese (Doutorado) - Curso de Engenharia e Gestão do Conhecimento, ECG, Universidade Federal de Santa Catarina, Florianópolis, 2009.

CORSELliS, T.; VITALE, A (Coords.). Transitional settlement: displaced populations. University of Cambridge: Oxfam. 2005. 239 p.

DATTA, Ayona. " Homed" in Arizona: The architecture of emergency shelters. Urban Geography, v. 26, n. 6, p. 536-557, 2005.

EM-DAT. The EM-DAT Atlas. c2020. Disponível em: https://www.emdat.be/emdat_atlas/. Acesso em: 18 jan. 2021.
FERES, Giovana Savietto. HABITAÇÃO EMERGENCIAL E TEMPORÁRIA: estudo de determinantes para o projeto de abrigos. 2014. 194 f. Dissertação (Mestrado) Universidade Estadual de Campinas, Campinas, 2014.

FERROLI, Paulo Cesar Machado; LIBRELOTTO, Lisiane Ilha; NASCIMENTO, Emanuele de Castro; MEDINA, Franchesca. Materiais para móveis: proposta de classificação. In: VII ENCONTRO DE SUSTENTABILIDADE EM PROJETO. Florianópolis, UFSC, 8-10 de maio de 2019. Anais VII ENSUS, 2019. v. 7. p. 656-669.

FERROLI, Paulo Cesar Machado; LIBRELOTTO, Lisiane Ilha; VIDIGAL, Maria Fernanda; SETTER, Diogo Alessandro. Sistema de leitura integrada amostras - site para classificação de materiais numa materioteca interdisciplinar. In: V ENSUS Encontro de Sustentabilidade em Projeto. Florianópolis, UFSC, 2-4 de Maio, 2017. Anais, p. 318-327.

GHOUSON, Amjad. Opening of a new school: $\mathrm{KG}$ classroom and inclusive playground in Zaatari Refugee Camp. Disponível em: <https://www.youtube.com/watch?v=4bIJ9F QYUMU>. Acesso: 2021.

GRAFTLAB. Solar Kioski. Disponível em: $<$ https://graftlab.com/solarkiosk-bringsinternet-power-schools-zaatari-refugeecamp/> Acesso: 2021.

LIBRELOTTO, Lisiane Ilha; FERROLI, Paulo Cesar Machado; MUTTI, Cristine do Nascimento; ARRIGONE, Giovani Maria. A Teoria do Equilíbrio - Alternativas para a Sustentabilidade na Construção Civil. Florianópolis: DIOESC, 2012. 


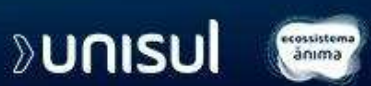

MATERIOTECA SUSTENTÁVEL. Catálogo

de Materiais. Disponível em:

$<$ http://materioteca.paginas.ufsc.br/>. Acesso em: 2021.

MOOK, Laurie; CHAN, Andrea; KERSHAW, Dan. Measuring social enterprise Value creation: The case of furniture bank. Nonprofit Management and Leadership, v. 26, n. 2, p. 189-207, 2015.

MONTEIRO, Cátia Maria Morgado. DESIGN PARA SITUAÇÕES DE EMERGÊNCIAEstudo centrado na intervenção do design aplicado em contextos periféricos. 2017. 190 f. Dissertação (Mestrado) - Curso de Design Industrial e de Produto, Belas Artes e Universidade do Porto, Porto, 2017.

MORENO-SIERRA, Andres; PIESCHACÓN, Mauricio; KHAN, Ahmed. The use of recycled plastics for the design of a thermal resilient emergency shelter prototype. International Journal of Disaster Risk Reduction v. 50, 2020, p. 1-14.

MSF. Jordan Border. Disponível em: $<$ https://www.msf.org/jordan-border-closureforces-msfs-clinic-war-wounded-syrianszaatari-refugee-camp-shut>. Acesso: 2021.

PASCUCCI, Elisa. Refugee Shelter in a Logistical World: Designing Goods for Supply-Chain Humanitarianism. Antipode, v. 53, n. 1, p. 260-278, 2021.

QUARANTELLI, Enrico Louis. Patterns of sheltering and housing in American disasters. 1991.

REFUGEES INTERNATIONAL. Zaatari refugee camp. Disponível em: < https://www.refugeesinternational.org/reports/ zaatari-camp-and-not-city>. Acesso em : 2021.

RELIEF WEB. Healf and epidemic. Outubro de 2020. Disponível em: <https://reliefweb.int/report/jordan/msfresponds-covid-19-arrives-jordan-s-largestrefugee-camp> Acesso em: 2021.

SPHERE ASSOCIATION. The Sphere Handbook: Humanitarian Charter and Minimum Standards in Humanitarian Response. 4.ed. Genevra. 2018.

VALENCIO, N.; MARCHEZINI, V.; SIENA, M. Após o desastre: abrigos temporários como loci de reafirmação da vulnerabilidade dos afetados pelas chuvas. In: REUNIÃO BRASILEIRA DE ANTROPOLOGIA, 26. , 2008, Porto Seguro. Anais da Reunião Brasileira de Antropologia. Porto Seguro: ABA, 2008. 